\title{
Ice friction: the effect of thermal conductivity
}

\author{
Anne-Marie KIETZIG,* Savvas G. HATZIKIRIAKOS, Peter ENGLEZOS \\ Department of Chemical and Biological Engineering, University of British Columbia, 2360 East Mall, \\ Vancouver, British Columbia V6T 1Z3, Canada \\ E-mail: hatzikir@interchange.ubc.ca
}

\begin{abstract}
The effect of thermal conductivity on ice friction is studied systematically for different metallic slider materials over a wide range of temperatures, and sliding velocities. By thermally insulating the slider with fiberglass, the isolated effect of thermal conductivity on ice friction is investigated. A decrease of the friction coefficient in the boundary friction regime and an earlier onset of the mixed friction regime in terms of sliding velocity are found. Furthermore, the dependence of the ice friction coefficient on sliding velocity is compared for different sliding materials. It is found that the influence and importance of thermal conductivity decreases with increasing sliding velocity.
\end{abstract}

\section{INTRODUCTION}

Friction is a major technological issue in almost every application that involves moving parts. Even though quantitative friction studies go back to Leonardo da Vinci (14521519), it was not until 150 years ago that friction on ice became the focus of scientific investigations. Ice is an inherently complex material. Its self-sustained lubricating meltwater film varies in thickness depending on the combined effect of parameters such as temperature, sliding velocity, applied normal force, contact area, roughness of slider and ice, wettability and surface structure, thermal conductivity and hardness of the slider material (Colbeck, 1994; Buhl and others, 2001; Bhushan, 2002). The thickness of the lubricating liquid-like layer defines which friction processes/mechanisms prevail, namely boundary, mixed and hydrodynamic friction (Persson, 2000; Bowden and Tabor, 2001; Bhushan, 2002).

Friction facilitated by a lubricating layer of no more than a few molecular layers is known as boundary friction. This thin layer reduces solid-solid contact at the interface, while the slider's load is mainly supported by the surface asperities (Kozlov and Shugai, 1991; Bhushan, 2002). In the mixed friction regime the load of the slider is supported by both the surface asperities and the lubricating layer, which is thicker than in the boundary friction regime. While this water film reduces solid-solid adhesion and enhances lubrication, it also results in the build-up of capillary bridges between the asperities (Colbeck, 1988). In the hydrodynamic friction regime the lubricating layer and not the surface asperities carries the applied load. The area of real contact is identical to the surface area, $A$, of the slider (Bhushan, 2002). No solid-solid contact occurs during the sliding movement. For a more in-depth explanation of the different friction regimes see Kietzig and others (2009, 2010).

Ice friction applications such as ice sports are characterized by a lubricating water film, which thickens towards the trailing end of the slider and thus involves all types of friction (Fowler and Bejan, 1993). Overall, however, the most relevant regime for ice sports is mixed friction, where both solid-solid contact and capillary drag play a significant role (Colbeck, 1994). Especially in sports such as speed skating, luge, skeleton and bobsleigh, ways to reduce friction on ice

*Present address: Department of Chemical Engineering, McGill University, Montreal, Québec, Canada. are sought (Rebsch and others, 1991; De Koning and others, 1992). The latter was the motivation for this work ahead of the 2010 Winter Olympic Games in Vancouver, Canada.

Most of the previous studies on ice friction report on the isolated effects of temperature (Bowden and Hughes, 1939; Evans and others, 1976; Calabrese and Buxton, 1980; Roberts and Richardson, 1981; Slotfeldt-Ellingsen and Torgersen, 1983; Akkok and others, 1987; Itagaki and others, 1987; Derjaguin, 1988; De Koning and others, 1992; Liang and others, 2003; Albracht and others, 2004; Higgins and others, 2008), sliding speed (Evans and others, 1976; Kuroiwa, 1977; Akkok and others, 1987; De Koning and others, 1992; Jones and others, 1994; Montagnat and Schulson, 2003; Albracht and others, 2004; Marmo and others, 2005; Bäurle and others, 2006), applied load (Bowden and Hughes, 1939; Oksanen and Keinonen, 1982; Akkok and others, 1987; Derjaguin, 1988; Buhl and others, 2001; Albracht and others, 2004; Bäurle and others, 2006), area of contact (Bowden and Hughes, 1939; Bäurle and others, 2007) and moisture (Calabrese and Buxton, 1980). Investigation of the effect of material-inherent parameters, such as thermal conductivity and surface wettability, is more complicated. This is because the use of materials of different thermal conductivity always brings along a change in other material parameters such as wettability and material hardness. Furthermore, a drastic change in one of these material-inherent parameters can easily change the prevailing friction regime. Therefore, it is not surprising that only a few experimental studies have emphasized the effects of thermal conductivity on ice friction (Bowden and Hughes, 1939; Itagaki and others, 1987; Albracht and others, 2004).

The very first report on experiments investigating the influence of thermal conductivity on ice friction was provided by Bowden and Hughes (1939). They compared the friction coefficient of a hollow ski with a copper surface with that of the same ski construction filled with mercury. Air has a thermal conductivity of about $0.025 \mathrm{~W} \mathrm{~m}^{-1} \mathrm{~K}^{-1}$ and mercury of $8 \mathrm{~W} \mathrm{~m}^{-1} \mathrm{~K}^{-1}$. The friction of the mercury-filled ski was found to be higher than that of the hollow air-filled ski. This result implies that the friction of a good thermal conductor is higher because less heat is available at the interface to melt the ice surface. The same relationship between thermal conductivity and the coefficient of friction on ice was found by Itagaki and others (1987) with three steels of different thermal conductivity. Albracht and others (2004) investigated the friction behavior of aluminum alloy, 

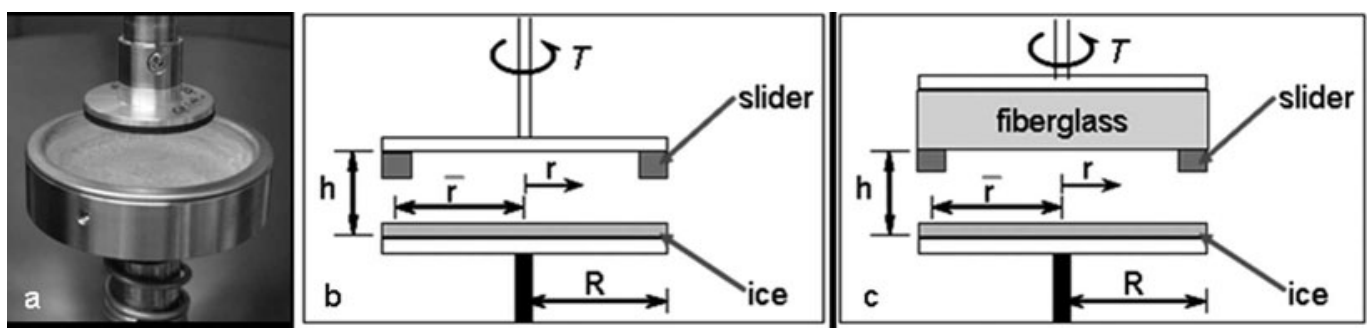

Fig. 1. Rheometer, (a, b) with newly designed friction fixture for ice friction experiments and (c) with fiberglass insulation.

alloy steel and PTFE. A significant influence of thermal conductivity on ice friction was not found. However, their conclusion was not demonstrated convincingly by their experimental results since the sliding velocity range and the friction regime of their experiments are unclear.

All empirical models based on the frictional heating theory include thermal conductivity of the slider as a major component in describing the meltwater film thickness and the resulting coefficient of friction (Evans and others, 1976; Oksanen and Keinonen, 1982; Stiffler, 1984, 1986; Akkok and others, 1987; Colbeck, 1988). Bäurle and others (2007) simulated the effect of thermal conductivity in their numerical model and found that an increase in thermal conductivity of the slider by a factor of 3 results in an increase of the friction coefficient by about $30 \%$ at $-5^{\circ} \mathrm{C}$. However, the only experimental findings confirming this dependency are from experiments conducted with few different materials (Bowden and Hughes, 1939; Itagaki and others, 1987).

In this paper, the isolated effect on ice friction of thermal conductivity and heat trapping at the interface is studied using fiberglass insulation for the slider. Results of ice friction experiments are presented for 14 different common engineering metal alloys and steels over a range of temperatures

Table 1. Slider and holder materials, their density, $\rho$, thermal conductivity, $k$, heat capacity, $c_{p}$, and contact angle, $\theta$, at $-7^{\circ} \mathrm{C}$

\begin{tabular}{|c|c|c|c|c|}
\hline \multirow[t]{2}{*}{ Material } & Density, $\rho$ & $\begin{array}{c}\text { Thermal } \\
\text { conductivity, } k\end{array}$ & $\begin{array}{c}\text { Heat capacity, } \\
c_{p}\end{array}$ & $\begin{array}{l}\text { Contact } \\
\text { angle, } \theta\end{array}$ \\
\hline & $\mathrm{kg} \mathrm{m}^{-3}$ & $W m^{-1} K^{-1}$ & $J \mathrm{~kg}^{-1} \mathrm{~K}^{-1}$ & 。 \\
\hline
\end{tabular}

\begin{tabular}{lcccc} 
Slider & & & & \\
TPG $^{\circledR}$ & 2260 & 6 & 710 & 88 \\
Ti-6-4 & 4430 & 7 & 520 & 54 \\
AISI 660 & 7920 & 12 & 460 & 69 \\
AISI 630 & 7750 & 13 & 460 & 74 \\
Stellite 6B & 8380 & 14 & 420 & 85 \\
Stellite 6K & 8380 & 14 & 420 & 86 \\
AISI 631 & 7800 & 15 & 460 & 68 \\
AISI 304L & 7900 & 15 & 500 & 90 \\
AISI D2 & 7830 & 16 & 460 & 91 \\
AISI M2 & 8100 & 19 & 410 & 92 \\
Nitinol & 6450 & 19 & 320 & 38 \\
AISI 420 & 7600 & 22 & 460 & 68 \\
AISI P20 & 7800 & 28 & 460 & 95 \\
AISI P20+Ni & 7800 & 32 & 460 & 66 \\
Holder & & & & \\
AISI 303 & 7800 & 14 & 500 & - \\
Aluminum & 2780 & 237 & 850 & - \\
Fiberglass & 100 & 0.04 & 844 & - \\
& & & & \\
\hline
\end{tabular}

and sliding velocities. Thereby a thorough analysis of the influence of thermal conductivity on ice friction across all relevant friction regimes is performed.

\section{METHODS AND MATERIALS}

Different materials, mainly metal alloys, were chosen as construction materials for the slider. They are listed in Table 1 with their respective thermal conductivity at $-7^{\circ} \mathrm{C}$ and contact angle as measured on the polished slider sample. As well as different steels and metal alloys, the list includes Nitinol and Momentive's TPG ${ }^{\mathbb{R}}$, which are unique materials. Nitinol is a superelastic nickel titanium shape-memory alloy. Under stress it changes its metallic crystal phase from austenitic to martensitic. After releasing the stress, this crystal transformation is fully reversible. Therefore, the plastic strain induced is largely recoverable and the alloy 'remembers' its shape. As a thermal management material, TPG ${ }^{\circledR}$ (thermal pyrolytic graphite) is another interesting material. Its in-plane thermal conductivity is as high as $k=1700 \mathrm{~W} \mathrm{~m}^{-1} \mathrm{~K}^{-1}$, while its thermal conductivity in the $\mathrm{z}$ direction is only about $6 \mathrm{~W} \mathrm{~m}^{-1} \mathrm{~K}^{-1}$. In the application of ice friction, this allows the frictional heat created at the interface to be distributed equally along the whole slider surface while only very little heat is conducted away into the slider.

The experimental set-up is shown in Figure 1. The ice and slider surface preparation are explained in detail elsewhere (Kietzig and others, 2009). In the following some key points are emphasized. The thin slider samples are mounted on an aluminum holder, which is held by a stainless-steel shaft in the experimental equipment. It is important to note that the aluminum holder serves as a heat sink due to its high thermal conductivity $\left(k=235-250 \mathrm{~W} \mathrm{~m}^{-1} \mathrm{~K}^{-1}\right)$ compared with the thermal conductivities of the sliders $\left(k=6-32 \mathrm{~W} \mathrm{~m}^{-1} \mathrm{~K}^{-1}\right)$.

The surfaces of the slider samples were polished to an average roughness value, $R_{\mathrm{a}}$ of about $600 \mathrm{~nm}$ using silicon carbide sandpaper. Care was taken to arrive at random polishing marks in all directions, as it was previously found that the orientation of these marks plays an important role in ice friction (Kietzig and others, 2009).

All slider samples were prepared in the shape of rings with an outer diameter of $25.4 \mathrm{~mm}$, an inside diameter of $21.4 \mathrm{~mm}$ and about $1 \mathrm{~mm}$ in thickness. For the ice friction experiments with thermally insulated sliders, a $3 \mathrm{~mm}$ thick fiberglass disk (thermal conductivity $k=0.04 \mathrm{~W} \mathrm{~m}^{-1} \mathrm{~K}^{-1}$ ) was mounted between the slider ring and the ring holder (Fig. 1c).

Before contact angle measurements were carried out on the polished surfaces, the samples were cleaned ultrasonically in acetone. Contact angle measurements were repeated six times at different locations along the slider ring to account for local variations in the surface roughness. 
The contact angles reported in Table 1 represent the average values of the local measurements of the advancing contact angles.

The ice friction experiments were carried out at a fixed normal force of $3 \mathrm{~N}$. Torque data recorded by the rheometer were averaged over 20-60s. This period falls within the transient state of heat conduction for our experimental set-up.

\section{RESULTS AND DISCUSSION}

\section{Thermal insulation of the slider with fiberglass}

To investigate the influence of thermal conductivity on ice friction, experiments were run with fiberglass-insulated metal sliders over a wide range of temperatures $\left(-1.5^{\circ} \mathrm{C}\right.$, $-4^{\circ} \mathrm{C},-7^{\circ} \mathrm{C}$ and $\left.-10^{\circ} \mathrm{C}\right)$ and sliding velocities (0.0036$1.4500 \mathrm{~m} \mathrm{~s}^{-1}$ ) in order to cover the relevant friction regimes. Our experimental set-up ensures constant and identical ice and ambient temperatures $\left( \pm 0.1^{\circ} \mathrm{C}\right)$. Since the thermal conductivity of ice is $2 \mathrm{~W} \mathrm{~m}^{-1} \mathrm{~K}^{-1}$, the frictional heat produced by the sliding motion at the interface and dissipated within the meltwater layer is conducted mainly through the sliders, the thermal conductivity of which is higher and in some cases considerably higher (Table 1). Fiberglass, with a thermal conductivity of $0.04 \mathrm{~W} \mathrm{~m}^{-1} \mathrm{~K}^{-1}$, prevents the heat from being conducted away from the iceslider interface along the ring holder. This results in a local temperature increase of the slider's interface.

The experimental results reported in this work represent an average of the torque recorded over a $40 \mathrm{~s}$ period, excluding the first $20 \mathrm{~s}$ of each experiment. A simple finite difference, unsteady, one-dimensional heat-transfer model (similar to that reported by Bäurle and others, 2007) for our experimental set-up simulates the heat flux through slider, insulation if applicable, holder and shaft. It was found that this period (20-60s) lies within the transient heat-transfer period (steady-state temperature has not been reached).

However, the relative differences between the surface temperatures of sliders of different thermal conductivity are manifested at the early stages of the process and hardly change with time (except that the profiles close to the surface are slowly translated to higher temperature). Therefore, it is possible to compare friction curves obtained from different slider materials and attribute these to differences in the thermal conductivity of the slider to a certain degree. This is due to the high thermal conductivity of the aluminum construction material of the slider holder. For the fiberglass experiments, however, the slope of the temperature gradients changes more significantly and the surface temperature reaches $0^{\circ} \mathrm{C}$ more rapidly. This creates a thicker water layer that reduces friction. Accordingly, these results do not allow for an intermaterial comparison of ice friction performance and can only be used to assess the effect of the insulation.

Figure 2 illustrates the frictional behavior of the material Stellite $6 B$ with and without insulation as a function of temperature and sliding velocity. In Figure 2a (Stellite 6B slider with no insulation), the friction coefficient initially decreases, passing through a minimum before it exhibits a slight increase at increasing velocity and independent of the temperature. After the minimum, an increase in the friction coefficient is noticed for velocities above about $1 \mathrm{~m} \mathrm{~s}^{-1}$, which can be attributed to added drag through capillary bridges (comparable to results from Colbeck's (1988)
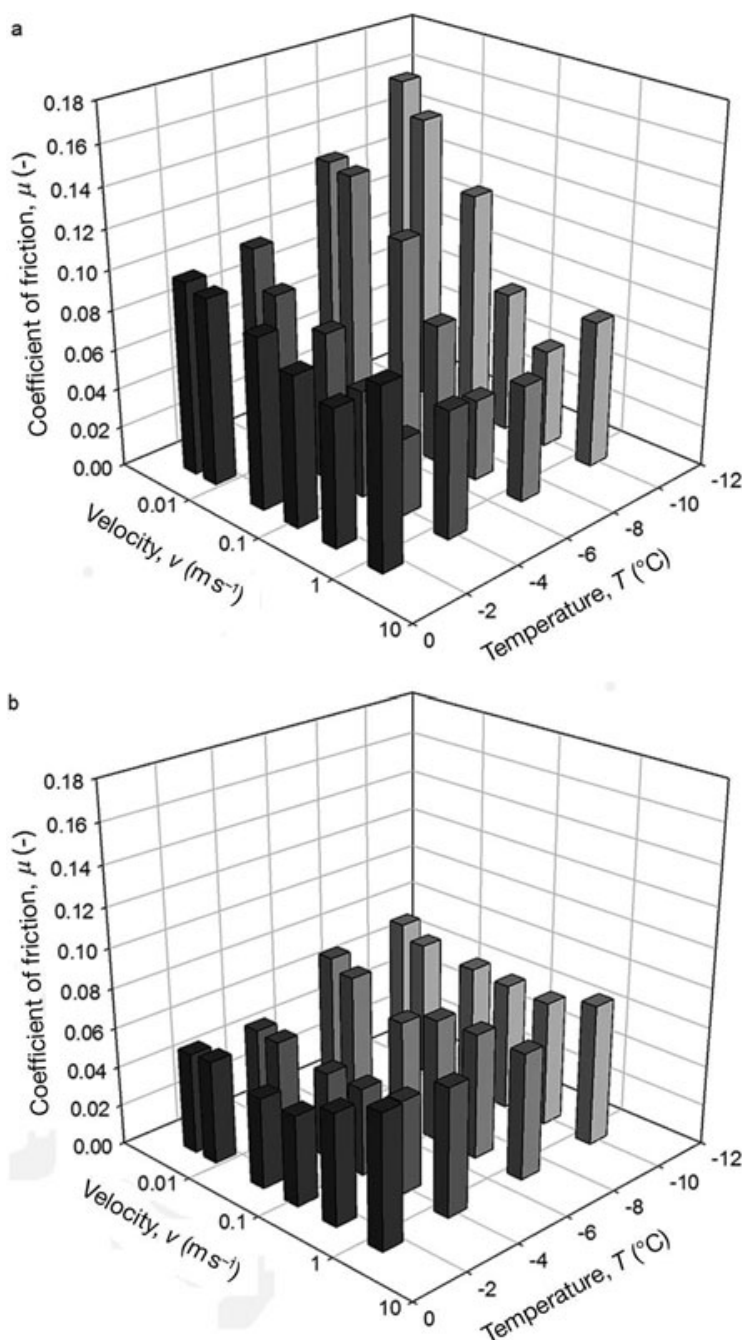

Fig. 2. 3-D bar chart of temperature and velocity dependence of the ice friction coefficient for (a) Stellite 6B and (b) Stellite 6B, insulated with a fiberglass disk.

theoretical investigations and other more recent experiments (Albracht and others, 2004; Bäurle and others, 2006)). Furthermore, at about $-4^{\circ} \mathrm{C}$ a minimum in the friction coefficient is observed. For temperatures below this minimum, the friction coefficient decreases with increasing temperature due to enhanced lubrication and reduced solidsolid contact. The opposite effect, an increase in friction with increasing temperature, for temperatures above $-4{ }^{\circ} \mathrm{C}$ results from the additional resistance caused by capillary bridges and viscous shearing of the melt film (Colbeck, 1988). A clear minimum in the coefficient of ice friction depending on temperature has also been reported by Calabrese and Buxton (1980), De Koning and others (1992) and Albracht and others (2004). Accordingly, this experimental set-up allows for investigations in the mixed friction regime, which is the most interesting since different mechanisms interplay.

Figure $2 b$ illustrates the ice friction behavior of the Stellite $6 \mathrm{~B}$ slider insulated with a fiberglass disk. It is apparent that the friction on ice for the slower velocities is much reduced. This indicates that the insulation traps the heat at the interface, raises the interface temperature quickly to the melting point, and therefore ensures a thicker lubricating layer, which again results in lower friction. The minimum sliding velocity, however, is shifted to lower speeds. The 

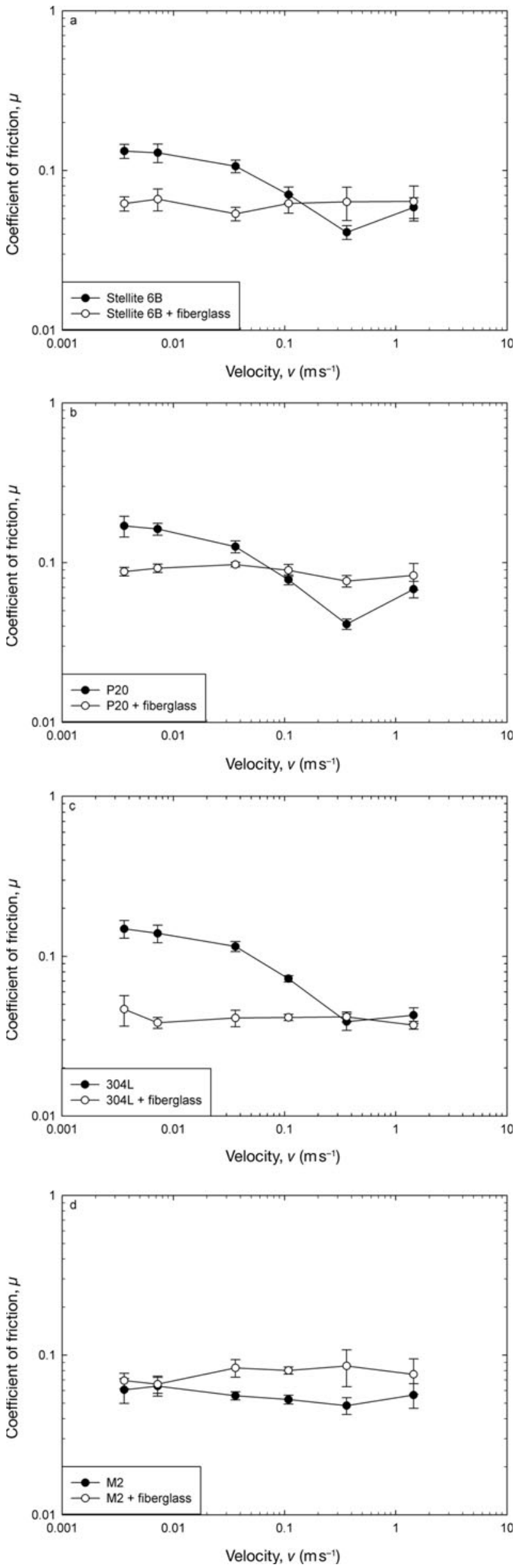

Fig. 3. Sliders with and without fiberglass insulation at $-7^{\circ} \mathrm{C}$ : (a) Stellite 6B, (b) AISI P20, (c) AISI 304L and (d) AISI M2. increase in friction towards hydrodynamic friction also starts at lower speeds and, comparing the two graphs, it is also clear that the minimum with the fiberglass insulation is at a higher friction coefficient than is the case for the noninsulated Stellite 6B slider.

Figure 3 illustrates the ice friction curves for different materials with and without fiberglass insulation at $-7^{\circ} \mathrm{C}$. Figure $3 a-c$ show the same trend. As described above, the fiberglass insulation greatly reduces the ice friction coefficient for low sliding velocities. This is expected in the boundary friction regime and at velocities lower than that at the friction minimum in the mixed friction regime, where interlocking asperities and little lubricating meltwater dominate the friction. Overall, the insulation dampens the friction curve, resulting in a wider mixed friction regime and a less pronounced minimum. For Stellite $6 \mathrm{~B}$ and AISI P20, the friction minima for the non-insulated slider lie noticeably below the fiberglass-insulated ice friction curves. In the case of AISI 304L, the curve for the insulated slider is at about the same level as the minimum for the non-insulated slider. However, for AISI M2, the ice friction curve of which is already low with a wide minimum, the fiberglass-insulated slider exhibits higher friction. This is comparable to Figure $3 \mathrm{a}$ and $\mathrm{b}$ for velocities around the minimum.

In conclusion, insulating the slider with fiberglass results in the frictional heat being trapped close to the interface and prevents its conduction along the sample holder. Therefore, more heat is available to melt the ice and lubricate the sliding interface. In the boundary friction regime and at velocities lower than that at minimum velocity in the mixed friction regime, this results in a decrease in friction, a wider mixed friction regime (Fig. $3 \mathrm{a}-\mathrm{C}$ ) and/or an earlier onset of the mixed friction regime (in terms of sliding velocity) (Fig. 3a). At the same time, the insulation and associated thicker meltwater layer can result in higher friction due to added capillary drag by water bridges around the friction minimum for particular sliders (Fig. 3a-d).

\section{The effect of thermal conductivity on the ice friction curve}

As is clear from the above discussion and the results presented in Figure 3, different materials have different ice friction curves under the same experimental settings. This is largely due to the different material compositions and the related material-inherent factors. One material-inherent factor is the thermal conductivity, as discussed above. However, the difference in the reaction to thermal insulation as illustrated in Figure 3 is also due to other material factors, such as surface wettability, surface roughness and material hardness.

Keeping the interaction of the different material-inherent factors in mind, it is clear that different materials exhibit different ice friction curves under identical experimental conditions. This is further illustrated in Figure 4. Generally, most materials follow the same typical friction curve with decreasing friction in the boundary friction regime, a minimum in the mixed friction regime and, depending on the location of the minimum, a subsequent increase in the friction coefficient with velocity. It is interesting to note that most materials show a minimum at the same velocity. However, on further investigation, it becomes clear that all these materials are steels, so this common characteristic is probably attributable to their similar chemical composition. 


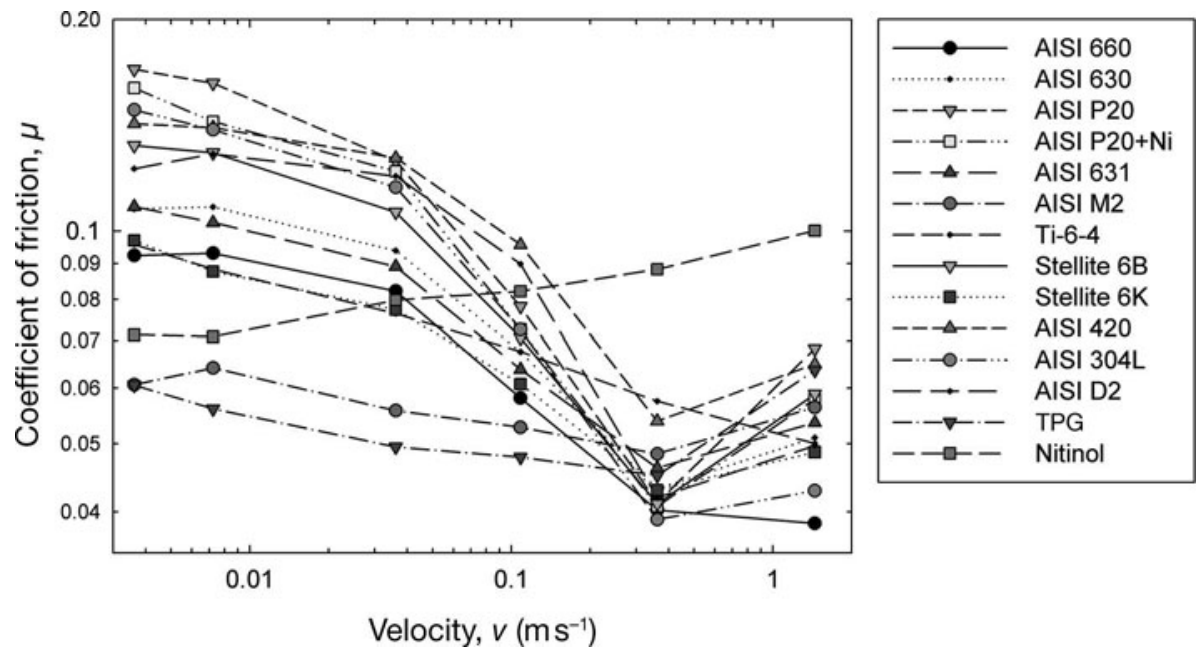

Fig. 4. Ice friction curves for different materials at $-7^{\circ} \mathrm{C}$.

Nitinol's friction curve, however, shows a significantly different behavior. Its friction coefficient increases continuously with the sliding velocity. Even at very slow sliding speeds, the behavior of this material is typical for the mixed friction regime past the minimum. This assumption is supported by the very high surface wettability of this material (Table 1), which enhances the build-up of capillary bridges, again contributing to the frictional resistance. However, such behavior might also be related to the change in Nitinol's crystal structure under stress. This material definitely offers ground for future research, and due to its atypical behavior it is excluded from the subsequent analysis.

It is also seen from Figure 4 that $\mathrm{TpG}^{\mathbb{B}}$ shows the lowest friction in the low-velocity range. This can be attributed to its non-uniform and non-isotropic thermal conductivity behavior. The in-plane thermal conductivity is very high, which ensures an even temperature across the whole surface and little difference between the temperature at the tips of surface asperities and spots that are not in contact with the ice. At the same time, the low thermal conductivity in the $z$ direction traps the frictional heat at the interface, resulting in a thick meltwater film and the lowest observed friction in the boundary regime.
Certainly the thermal conductivity of the different materials plays a significant role in the observed behavior, although other material properties might also be important but are difficult to assess. From the heat-transfer model of Bäurle and others (2007), an increase in the thermal conductivity of the slider by a factor of 3 causes an increase in the coefficient of friction by about $30 \%$ at $-5^{\circ} \mathrm{C}$. In our case, the thermal conductivity of P20 is four times that of Ti-6-4. Taking the three slowest velocities at $-7^{\circ} \mathrm{C}$ (Fig. 4), the friction coefficient of P20 is found to be 65$85 \%$ higher than that of Ti-6-4. Similarly, taking the thermal conductivity of P20, which is twice that of Stellite $6 \mathrm{~B}$, the friction coefficient of P20 is found to be $15-25 \%$ higher than that of Stellite $6 \mathrm{~B}$. These results seem reasonable with respect to the trend described by Bäurle and others (2007). It is noted that the experimental conditions of the present work are similar to those used by Bäurle and others (2007) except that they used a much higher normal force, i.e. $84 \mathrm{~N}$ vs $3 \mathrm{~N}$ used in the present work.

A simple correlation analysis is now performed to show how far the obtained friction results across different materials can be attributed to their thermal conductivity. Figure 5 summarizes the contribution of thermal conductivity to ice

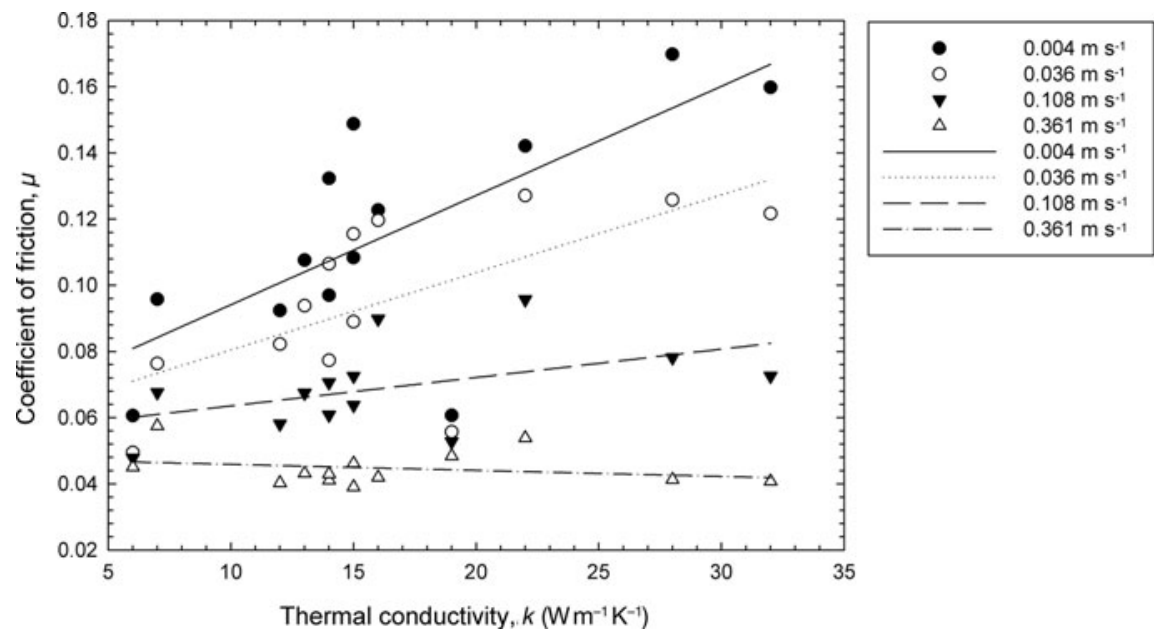

Fig. 5. The contribution of thermal conductivity to ice friction at different sliding velocities. 


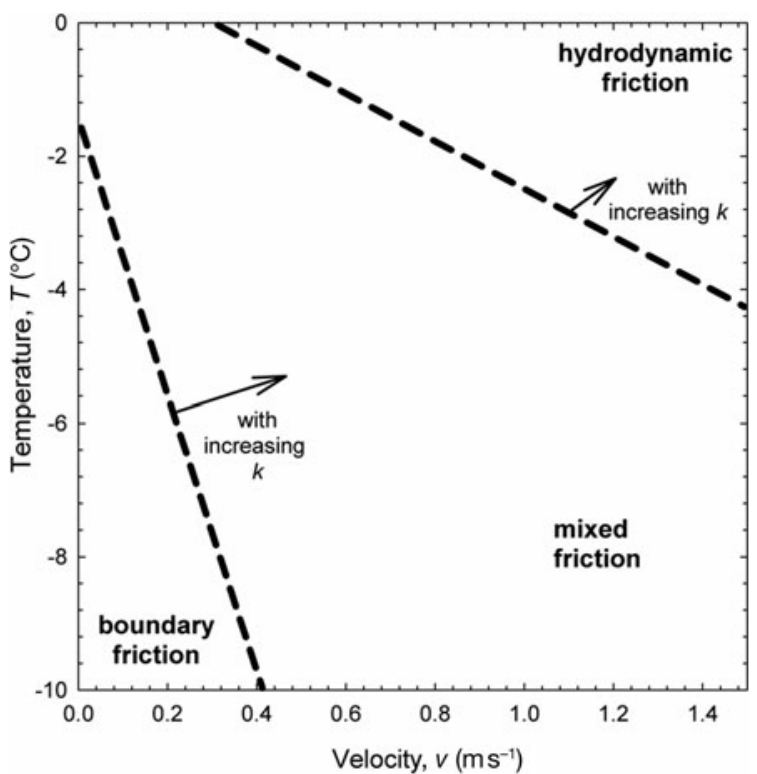

Fig. 6. Qualitative friction map on the influence of thermal conductivity on the different friction regimes depending on temperature and sliding velocity. The boundaries between the friction regimes are set qualitatively to illustrate a trend and are not necessarily linear.

friction across different materials at different sliding velocities. To show the trend, linear regressions are plotted through the data for different sliding velocities. Table 2 summarizes the slopes of the different lines and their respective fit to the data. The slope of the trend lines, $\mathrm{d} \mu / \mathrm{d} k$, and especially the Bravais-Pearson correlation coefficient, $\left(R_{k}, v\right)$ show clearly that for very low sliding velocities there is a positive dependency of the friction coefficient on thermal conductivity. With increasing sliding velocities, this dependency decreases until $v=0.361 \mathrm{~m} \mathrm{~s}^{-1}$, which is the velocity where many materials display a minimum in the ice friction coefficient. This again indicates that at velocities lower than that at the minimum (in the regime of boundary and mixed friction) higher thermal conductivity of the slider material results in more heat being conducted away into the slider, so that less heat remains available to melt the ice at the interface and to contribute to lubrication.

\section{SUMMARY AND CONCLUSION}

The effect of thermal conductivity on ice friction was studied systematically over a wide range of temperatures and sliding velocities by insulating slider materials with fiberglass and by comparing different materials. It has been shown that the more heat is trapped at the interface due to low thermal conductivity of the sliding material or the presence of thermal insulation, the lower is the friction coefficient at the boundary and partly in the mixed friction regime, where interlocking asperity contacts contribute to the frictional resistance. Generally, thermal insulation dampens the friction curves and widens the mixed friction regime. Figure 6 summarizes these findings in a qualitative friction map.

The influence of thermal conductivity on the exact location and height of the ice friction minimum is not straightforward, as other material-inherent factors, such as surface wettability and material hardness, also play a significant role (Kietzig and others, 2009, 2010). Overall, it was demonstrated by the comparison of many different slider materials that thermal conductivity loses its influence on ice friction with increasing sliding velocity, while surface wettability gains importance.

\section{ACKNOWLEDGEMENTS}

Financial support from Own The Podium (OTP) 2010 of the Vancouver Olympic Committee (VANOC) is gratefully acknowledged. We also appreciate valuable discussions with T. Allinger of OTP 2010.

\section{REFERENCES}

Akkok, M., C.M.M. Ettles and S.J. Calabrese. 1987. Parameters affecting the kinetic friction of ice. J. Tribol., 109(3), 552-561.

Albracht, F., S. Reichel, V. Winkler and H. Kern. 2004. On the influences of friction on ice. Materialwiss. Werkstofftech. 35(10/11), 620-625.

Bäurle, L., D. Szabó, M. Fauve, H. Rhyner and N.D. Spencer. 2006. Sliding friction of polyethylene on ice: tribometer measurements. Tribol. Lett., 24(1), 77-84.

Bäurle, L., T.U. Kaempfer, D. Szabó and N.D. Spencer. 2007. Sliding friction of polyethylene on snow and ice: contact area and modeling. Cold Reg. Sci. Technol., 47(3), 276-289.

Bhushan, B. 2002. Introduction to tribology. New York, Wiley.

Bowden, F.P. and T.P. Hughes. 1939. The mechanism of sliding on ice and snow. Proc. R. Soc. London, Ser. A, 172(949), 280-298.

Bowden, F.P. and D. Tabor. 2001. The friction and lubrication of solids. Third edition. Oxford, etc., Oxford University Press.

Buhl, D., M. Fauve and H. Rhyner. 2001. The kinetic friction of polyethylene on snow: the influence of the snow temperature and the load. Cold Reg. Sci. Technol., 33(2-3), 133-140.

Calabrese, S.J. and M.J. Buxton. 1980. Frictional characteristics of materials sliding against ice. Lubr. Eng., 36(5), 283-289.

Colbeck, S.C. 1988. The kinetic friction of snow. J. Glaciol., 34(116), 78-86.

Colbeck, S.C. 1994. A review of the friction of snow skis. J. Sports Sci., 12(3), 285-295.

De Koning, J.J., G. de Groot and G.J. van Ingen Schenau. 1992. Ice friction during speed skating. J. Biomech., 25(6), 565-571.

Derjaguin, B.V. 1988. Mechanical properties of the boundary lubrication layer. Wear, 128(1), 19-27.

Evans, D.C.B., J.F. Nye and K.J. Cheeseman. 1976. The kinetic friction of ice. Proc. R. Soc. London, Ser. A, 347(1651), 493-512.

Fowler, A.J. and A. Bejan. 1993. Contact melting during sliding on ice. Int. J. Heat Mass Transfer, 36(5), 1171-1179.

Higgins, D.D., B.A. Marmo, C.E. Jeffree and V.B.J.R. Koutsos. 2008. Morphology of ice wear from rubber-ice friction tests and its dependence on temperature and sliding velocity. Wear, $\mathbf{2 6 5}$ (5-6), 634-644.

Itagaki, K., G. Lemieux and N. Huber. 1987. Preliminary study of friction between ice and sled runners. J. Phys. [Paris], 48(3), 297-301. (Colloq. C1.)

Jones, S.J., H. Kitagawa, K. Izumiyama and H. Shimoda. 1994. Friction of melting ice. Ann. Glaciol., 19, 7-12.

Kietzig, A.-M., S.G. Hatzikiriakos and P. Englezos. 2009. Ice friction: the effects of surface roughness, structure, and hydrophobicity. J. Appl. Phys., 106(2), 024303. (10.1063/1.3173346.)

Kietzig, A.-M., S.G. Hatzikiriakos and P. Englezos. 2010. Physics of ice friction. J. Appl. Phys. 107(8), 081101. (10.1063/ 1.3340792.

Kozlov, I.I. and A.A. Shugai. 1991. Experimental study of highspeed friction on ice. Fluid Dyn., 26(1), 145-147. 
Kuroiwa, D. 1977. The kinetic friction on snow and ice. J. Glaciol., 19(81), 141-152.

Liang, H., J.M. Martin and T.L. Mogne. 2003. Experimental investigation of friction on low-temperature ice. Acta Mater., 51(9), 2639-2646.

Marmo, B.A., J.R. Blackford and C.E. Jeffree. 2005. Ice friction, wear features and their dependence on sliding velocity and temperature. J. Glaciol., 51(174), 391-398.

Montagnat, M. and E.M. Schulson. 2003. On friction and surface cracking during sliding of ice on ice. J. Glaciol., 49(166), 391-396.

Oksanen, P. and J. Keinonen. 1982. The mechanism of friction of ice. Wear, 78(3), 315-324.
Persson, B.N.J. 2000. Sliding friction: physical principles and applications. Second edition. Berlin, Springer-Verlag.

Rebsch, H., M. Jost, K. Debus, H. Bosse and G. Fleischer.1991. Optimierung des Gleitverhaltens zwischen metallischen Kufenwerkstoffen und Eis. Tribol. Schmierungstech., 38(6), 346-351.

Roberts, A.D. and J.C. Richardson. 1981. Interface study of rubberice friction. Wear, 67(1), 55-69.

Slotfeldt-Ellingsen, D. and L. Torgersen. 1983. Water in ice: influence on friction. J. Phys. D, 16(9), 1715-1719.

Stiffler, A.K. 1984. Friction and wear with a fully melting surface. J. Tribol., 106(3), 416-419.

Stiffler, A.K. 1986. Melt friction and pin-on-disc devices. J. Tribol., 108(1), 105-108.

MS received 3 October 2009 and accepted in revised form 18 March 2010 